\title{
COLON SPECIFIC DELIVERY OF COMBINATION OF 5-FLUOROURACIL AND CELECOXIB: PREPARATION, CHARACTERIZATION, AND IN VITRO CYTOTOXICITY ASSAY
}

\author{
VIKAS BANSAL ${ }^{1,2 *}$, ANJOO KAMBOJ ${ }^{1}$, JITENDER MADAN ${ }^{1}$ \\ ${ }^{1}$ Department of Pharmaceutics, Chandigarh College of Pharmacy, Mohali, Punjab, India. ${ }^{2}$ I.K. Gujral Punjab Technical University, Jalandhar, \\ Punjab, India. Email: vikasbansal16@gmail.com
}

Received: 22 September 2018, Revised and Accepted: 14 November 2018

\section{ABSTRACT}

Objective: 5-Fluorouracil(5-FU) and celecoxib (Cel)combination offered additive effectin thetreatment of coloncancer. However, physicochemical and biopharmaceutical attributes of both drugs deliver suboptimal concentration at the site of action.

The objective of the current study is the development of a microparticulate drug delivery system loaded with a combination of 5-FU and Cel to achieve prolonged drug delivery in colon cancer.

Methods: 5-FU and Cel combination were loaded in Eudragit coated chitosan ( $\mathrm{CH}$ ) microspheres (MSs) and characterized.

Results: The average particle size of the MSs was in the range of $2.7 \pm 0.9 \mu \mathrm{m}$ to $4.8 \pm 1.1 \mu \mathrm{m}$. A substantial drug encapsulation efficiency of $71.30 \pm 2.3 \%$ as obtained for 5 -FU as compared to $35.20 \pm 1.9 \%$ of Cel in the tailored microparticles. The drug loading capacity of $6.5 \mathrm{mg} / 10 \mathrm{mg}$ and $2.3 \mathrm{mg} / 10 \mathrm{mg}$ was obtained for 5-FU and Cel, respectively. By Eudragit S 100 (Ed) coating, significant pH-dependent release profile was achieved, and no drug release was observed in simulated gastric and intestinal fluids. The developed MSs exhibited the release of $92.1 \pm 2.9 \%$ of 5 -FU in $8 \mathrm{~h}$ whereas $18.9 \pm 0.7 \%$ Cel was

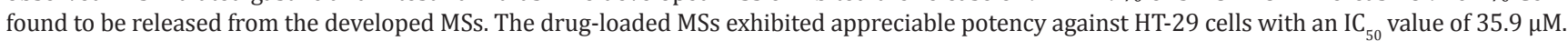

Conclusion: The results indicated that these microparticles are a promising vehicle for selectively targeting drugs to the colon in the chemotherapy of colon cancer.

Keywords: 5-Fluorouracil, Celecoxib, Chitosan, Eudragit coating, Colon targeting, Cytotoxicity.

(C) 2019 The Authors. Published by Innovare Academic Sciences Pvt Ltd. This is an open access article under the CC BY license (http://creativecommons. org/licenses/by/4. 0/) DOI: http://dx.doi.org/10.22159/ajpcr.2019.v12i3.29876

\section{INTRODUCTION}

Colorectal cancer (CRC) is the third leading cause of death in all kinds of cancer after lung and liver cancer followed by stomach and breast cancer [1]. The occurrence of CRC varies globally, and more number of cases is reported in countries such as North America, Japan, Australia, Western Europe, and New Zealand [2]. Very few cases of CRC are connected with genetic disorders [3,4].

5-Fluorouracil (5-FU), a synthetic pyrimidine antimetabolite is the most effective and first line drug for the treatment of CRC [5]. Despite its efficacy against CRC, 5-FU suffers from several drawbacks including a short biological half-life, invariable oral bioavailability, the requirement of multiple dosages for successful chemotherapy, and gradual increase in the drug resistance [6]. This chemotherapeutic agent is administered as continuous intravenous infusion which causes side effects in nontargeted organs also.

5-FU also has cardiotoxic potential including angina pectoris, myocardial infarction, arrhythmias, heart failure, and cardiogenic shock [7]. 5-FU also reduces the heart pump capacity which leads to heart insufficiency due to scattered necrosis with loss of cardiomyocytes [8].

Various studies have demonstrated the role of nonsteroidal antiinflammatory drugs in decreased risk of CRC [9]. Epidemiologic, clinical and laboratory-based investigations distinguished cyclooxygenase-2 (COX-2) as a potential molecular target, responsible for the production of PGs which stimulates cancer-associated angiogenesis [4]. Furthermore, it is also documented that the COX-2 levels are increased in $85 \%$ of human colorectal adenocarcinomas $[10,11]$. Therefore, selective COX2 inhibitors like celecoxib (Cel) hold a very good application prospect for the prevention and treatment of colon cancer [6]. A study was conducted on the role of Cel in familial adenomatous polyposis (FAP) which shows twice daily dose of $400 \mathrm{mg}$ of Cel significantly reduced the number and size of colorectal polyps [12]. Cel is approved by US Food and Drug Administration in the patients of FAP as add-on therapy to inhibit the growth of adenomatous polyps [13,14].

Studies conducted in the past revealed the synergistic effect of Cel when combined with 5-FU to retard the growth of colon tumor. Induced apoptosis of colon tumor cells and considerable tumor regression along with increased COX-2 inhibition was manifested in a subcutaneous implantation tumor model of HT-29 colon cancer cell line. Treated group of nude mice exhibited induced expression of cytochrome $\mathrm{C}$, caspase-3, and caspase-9 indicative of apoptosis [6]. Chemosensitivity of 5-FU resistant cells was improved when exposed to the combination of 5-FU and Cel [11].

Various approaches have been developed for site-specific drug delivery of anticancer molecule in the colon, which may lead to a substantial decrease in the dose and dose-related side effects. Techniques such as $\mathrm{pH}$-dependent systems, pressure dependent formulations, timedependent approaches, and bacteria dependent systems are reported in literature $[15,16]$.

Chitosan (CH), a cationic polysaccharide is a natural polymer obtained by treating chitin with sodium hydroxide and gained tremendous importance in the field of colon delivery. Due to its unique properties such as biodegradability, biocompatibility, and low toxicity, it has attracted the attention of formulation scientists for the fabrication of colon targeted tablets, beads, microparticles, and nanoparticles enable them to release the drug in colonic milieu $[17,18]$. It has been used 
successfully in the delivery of drugs such as valdecoxib, 5-FU, curcumin, icariin, and vancomycin [19-24].

Ed, a pH-sensitive polymer protects the loss of drug in the upper gastrointestinal tract and subsequently results in the successful delivery of drugs in the colon only. Ed coating is already been used by formulation scientist for the successful delivery of 5-FU and valdecoxib $[19,20]$

Therefore, in the present investigation, a combination of 5-FU and Cel was loaded in Ed coated CH-microspheres (MSs) as a novel approach to deliver the "cocktail of therapeutic moities" for the management of colon cancer. 5-FU and Cel combination loaded Ed coated CH-MSs were prepared by two methods, namely emulsion polymerization and nonaqueous solvent evaporation methods for investigating the effect on particle size and entrapment efficiency (EE). Both types of MSs were characterized with particle size analyzer, transmission electron microscope (TEM), EE, drug loading capacity, Fourier transform infrared spectroscopy (FTIR), X-ray diffraction (XRD), and differential scanning calorimetry (DSC). The optimized formulation was further characterized for in vitro drug release and cytotoxicity analysis against human colon cancer cell line, HT-29 following standard cell proliferation assay.

\section{MATERIALS AND METHODS}

\section{Materials}

5-FU was purchased from CDH-Laboratory Chemicals India, whereas Cel was obtained as a gift sample from Cadila Pharmaceutical, Ahmadabad, India. HT-29 human colon cancer cell lines were purchased from NCS, Pune, India. $\mathrm{CH}$ and Ed were procured from HiMedia Laboratories, Mumbai, India. Glutaraldehyde (GA) and span 80 were purchased from Loba Chemie, Mumbai, India. Acetonitrile and water (high-performance liquid chromatography [HPLC] grade) were purchased from Fisher Scientific, Mumbai, India. All other reagents and chemicals were of analytical grade.

\section{Cell culture and reagents}

Human colon cancer cell lines (HT-29) were maintained at $37^{\circ} \mathrm{C}$ in $\mathrm{CO}_{2}(5 \%)$, and air $(95 \%)$ with Dulbecco's modified eagle medium (DMEM) enriched with fetal bovine serum (10\%).

\section{Methods}

\section{Preparation of drug loaded CH-MSs byan emulsion polymerization} method

Emulsion polymerization method was employed for the development of CH-MSs loaded with 5-FU and Cel. In brief, a weighed quantity of $\mathrm{CH}$ (200 mg) was dissolved in $15 \mathrm{ml}$ of 5\% acetic acid, and $475 \mathrm{mg}$ of 5-FU and $200 \mathrm{mg}$ of Cel was added to it. This drug-polymer dispersion was added dropwise with the help of hypodermic syringe in a $150 \mathrm{ml}$ liquid paraffin ( $75 \mathrm{ml}$ light liquid paraffin $+75 \mathrm{ml}$ heavy liquid paraffin) containing $1 \% \mathrm{w} / \mathrm{w}$ span 80 and it was stirred with the help of mechanical stirrer for $1 \mathrm{~h}$ at 2500 revolutions per minute (RPM) and a temperature of $70^{\circ} \mathrm{C}$. After $1 \mathrm{~h}$ a saturated solution of cross-linking agent (10 ml GA: $30 \mathrm{ml}$ toluene) was added and stirred continuously until $2 \mathrm{~h}$ at $55^{\circ} \mathrm{C}$. Suspension of cross-linked CH-MSs in paraffin oil thus obtained was allowed to stand for $20 \mathrm{~min}$ to let the MSs settle down under gravity. MSs were separated by filtration and washed several times with n-hexane to remove traces of the oil and finally with water to remove excess of GA. The MSs were dried at room temperature for $24 \mathrm{~h}$ and stored in desiccators [25].

\section{Preparation of drug loaded CH-MSs by nonaqueous solvent} evaporation method

Nonaqueous solvent evaporation method was also used to prepare CH-MSs. In a nutshell, a weighed quantity of $\mathrm{CH}(250 \mathrm{mg})$ was dissolved in $10 \mathrm{ml}$ of acetone, and the combination of 5-FU (475 mg) and Cel (200 mg) was added to it. The prepared slurry was added into $30 \mathrm{ml}$ of liquid paraffin. The mixture was stirred with the help of mechanical stirrer at the speed of 1200 RPM for $4 \mathrm{~h}$ at room temperature. MSs were obtained after evaporation of the solvent and further washed repeatedly with petroleum ether to remove traces of oil and acetone. The washed MSs were stored at room temperature for $3 \mathrm{~h}$ and subsequently stored in desiccators [26].

Coating of drug loaded CH-MSs by an emulsification-solvent evaporation method

Emulsification-solvent evaporation method was employed for the coating of 5-FU and Cel loaded CH-MSs with Ed. The prepared drug-loaded CHMSs $(100 \mathrm{mg})$ were coated with $10 \mathrm{ml}$ of $10 \% \mathrm{w} / \mathrm{v}$ ethanolic solution of Ed. Light liquid paraffin $(70 \mathrm{ml})$ and span $80(1 \% \mathrm{v} / \mathrm{v})$ was added for emulsification followed by stirring for $3 \mathrm{~h}$ at $1000 \mathrm{RPM}$ at room temperature for removal of the solvent by evaporation. The prepared drugloaded Ed-CH-5-FU-Cel-MSs were filtered and washed with n-hexane and dried at room temperature and stored in desiccators [21,27].

\section{Characterization of drug loaded MSs}

\section{FTIR spectroscopy}

FTIR spectrum of 5-FU, Cel, physical mixture of 5-FU and Cel (5-FUCel-PM), Physical mixture of $\mathrm{CH}$ and Ed with both the drug molecules under investigation (Ed-CH-5-FU-Cel-PM) and Ed-CH-5-FU-Cel-MSs was recorded using infrared spectrophotometer (Alpha-E) utilizing $\mathrm{KBr}$ disc method ( $2 \mathrm{mg}$ sample in $200 \mathrm{mg} \mathrm{KBr}$ ). The scanning range selected for the study was $4000-400 \mathrm{~cm}^{-1}$ at a resolution of $4 \mathrm{~cm}^{-1}$.

DSC

DSC thermograms were recorded for 5-FU-Cel-PM and Ed-CH-5-FUCel-MSs using DSC (Mettler Toledo, 822e, Griefensee, Switzerland). All samples were hermetically sealed in crimped aluminum pan and subsequently heated at a temperature range of $30-300^{\circ} \mathrm{C}$ and cooling rate of $10^{\circ} \mathrm{C} / \mathrm{min}$ in an inert environment of nitrogen gas.

\section{Powder XRD (PXRD)}

$X$-ray pattern of the selected samples was recorded using X-ray diffractometer (X'Pert PRO, Panalytical Company, Netherlands). Nickel filtered, $\mathrm{CuK} \alpha$ radiations generated at a voltage of $60 \mathrm{kV}$ and $50 \mathrm{~mA}$ current were employed for study at a scanning rate of $1^{\circ} /$ min over the diffraction angle $(2 \theta)$ range of $10-60^{\circ}$. PXRD diffractograms of 5-FU, Cel, and Ed-CH-5-FU-Cel-MSs were recorded and analyzed.

\section{Particle size analysis}

The mean particle size distribution of prepared Ed-Ch-5FU-Cel-MSs was calculated by laser diffractometry using Mastersizer 2000, Melvern Instruments Ltd. for dry powder measurement. The accurately weighed MSs $(20 \mathrm{mg}$ ) were dispersed in HPLC water and visualized for particle size distribution $[28,29]$.

\section{TEM}

The shape and surface morphology of the developed Ed coated CH-MSs was investigated using TEM (FTI Tecnai F20). An aqueous suspension of MSs was drop cast onto a carbon coated grid which was then air dried at room temperature before loading into a microscope, maintained at a voltage of $80 \mathrm{kV}$

\section{Drug EE and drug loading capacity}

Drug EE\% of 5-FU and Cel in the developed MSs was determined using an HPLC method. For this purpose, precisely weighed $(10 \mathrm{mg})$ of coated MSs were added into $10 \mathrm{ml}$ of acetonitrile:water (50:50) mixture and subjected to centrifugation at 1500 RPM for $10 \mathrm{~min}$. The resulting clear centrifuge $(2 \mathrm{ml})$ was pipetted out and filtered through $0.45 \mu \mathrm{m}$ membrane filter. $20 \mu \mathrm{L}$ of this filtered solution was then injected into HPLC column and analyzed at $260 \mathrm{~nm}[28,29]$.

The percent drug EE and drug loading capacity were calculated using the following equations: 
$\mathrm{EE}(\%)=$ Actual drug loading/Theoretical drug loading $\times 100$ DLC=Drug weight within the microspheres/weight of microspheres

\section{In vitro drug release studies}

Ed-CH-5FU-Cel-MSs were evaluated for in vitro drug release in $\mathrm{pH}$ progression medium at $37^{\circ} \mathrm{C} \pm 0.5^{\circ} \mathrm{C}$. The dissolution study was performed using the paddle method. Accurately weighed coated MSs $(100 \mathrm{mg}$ ) were deliberately spread over the surface of $900 \mathrm{ml}$ of dissolution medium. The content was rotated at $50 \mathrm{RPM}$. To compare the release of 5-FU and Cel under different GI transit condition, the $\mathrm{pH}$ of the dissolution medium was altered at different time intervals. The experiments were performed in an acidic buffer $(\mathrm{pH} \mathrm{2.0)}$ for $2 \mathrm{~h}$, which simulates the condition of the fasted stomach. After that, the study was conducted in the phosphate buffer $(\mathrm{pH} 4.5)$ to simulate duodenum for $2 \mathrm{~h}$ followed by in phosphate buffer ( $\mathrm{pH}$ 6.8), which simulates mid jejunum. Finally, drug release study was continued in phosphate buffer (pH 7.4) to simulate ileo-colonic conditions for the next $2 \mathrm{~h}$. Sample (5 ml) was withdrawn at specific time intervals (after 5, 15, 30, and $60 \mathrm{~min}$ for $1^{\text {st }} \mathrm{h}$, afterward every hour till the end of the study) and replaced with fresh dissolution medium to mimic finite sink conditions. The samples were passed through a microfilter and analyzed by HPLC for estimation of drug release. The dissolution study was performed in triplicate $[20,21,29,30]$

\section{In vitro cytotoxicity assay}

3-[4,5-dimethylthiazol-2-yl]-2,5 diphenyltetrazolium bromide (MTT) assay, a standard colorimetry based assay was selected for the determination of cytotoxicity. HT-29 human colon cancer cell line was cultured in a 96 well microtiter plate. Briefly, HT-29 cells were implanted in $200 \mu \mathrm{L}$ of the serum DMEM medium at a density of $5 \times 10^{3}$ cells per well. After the incubation period of $24 \mathrm{~h}$, the medium was replaced with serum-free-DMEM. After $24 \mathrm{~h}$, the HT 29 cells were exposed to 5-FU, Cel, 5-FU-Cel, Ed-CH-5-FU-Cel-MSs and blank MSs (Bl-MSs) equivalent to $10-70 \mu \mathrm{M}$ of $5-\mathrm{FU}$ and Cel for $72 \mathrm{~h}$. At the end of the treatment, the medium was removed and the cells were treated with $0.5 \mathrm{mg} / \mathrm{ml}$ of MTT dye for $4 \mathrm{~h}$ at $37^{\circ} \mathrm{C}$. The HT 29 cells were lysed and thus formed formazan crystals were dissolved in $100 \mu \mathrm{L}$ of DMSO and quantified by ELISA reader at $570 \mathrm{~nm}$ and $630 \mathrm{~nm}$. The experiments were performed in triplicate $(n=3)$ [31-33].

\section{RESULTS AND DISCUSSION}

\section{Preparation and characterization of MSs}

Ed-CH-5-FU-Cel-MSs were prepared by emulsion polymerization method and characterized under a set of stringent parameters [25].

\section{Characterization of MS}

\section{FTIR spectroscopy}

The results of the FTIR spectrum of 5-FU, Cel, 5-FU-Cel-PM, Ed-CH5-FU-Cel-PM and Ed-CH-5-FU-Cel-MSs are shown in Table 1. FTIR spectrum showed characteristic peak due to pure 5-FU at 1641 and $1229 \mathrm{~cm}^{-1}$ correspond to the $\mathrm{C}=0$ and $\mathrm{C}-\mathrm{X}$, respectively. The spectrum of Cel showed a characteristic peak at 3331,1345, and $1138 \mathrm{~cm}^{-1}$ due to $\mathrm{N}-\mathrm{H}$ stretching and $\mathrm{S}=\mathrm{O}$ stretching vibrations of sulfonamide. In 5-FU-Cel-PM a slight shift was observed at 1226 and $1138 \mathrm{~cm}^{-1}$ from the original peaks of 5-FU and Cel, respectively. The spectrum of EdCH-5-FU-Cel-MSs indicated that characteristic peaks of 5-FU, Cel, and Ed are present in the PM of drugs and excipients as well as in the drug-loaded MSs. However, broadening and decrease in peak intensity were observed in the spectrum of drug loaded MSs which indicated no chemical interaction between drug and polymer [21].

DSC

DSC thermograms of 5-FU-Cel-PM along with Ed-CH-5-FU-Cel-MSs are presented in Fig. 1. A sharp endothermic peak at $162.02^{\circ} \mathrm{C}$ was observed for $5-\mathrm{FU}$, close to its investigated melting point $\left(158^{\circ} \mathrm{C}\right)$. On
Table 1: FTIR assignment of 5-FU, Cel, 5-FU-Cel-PM, Ed-CH-5-FU-Cel-PM and Ed-CH-5-FU-Cel-MSs

\begin{tabular}{lll}
\hline Sample & Peak & Assignment \\
\hline 5-FU & 1641 & $\mathrm{C}=0$ \\
& 1229 & $\mathrm{C}-\mathrm{X}$ \\
Cel & 3331 & $\mathrm{~N}-\mathrm{H}$ stretching \\
& 1345 and 1138 & $\mathrm{~S}=0$ stretching \\
5-FU-Cel-PM & 1345 and 1147 & $\mathrm{~S}=0$ stretching \\
& 1226 & $\mathrm{C}-\mathrm{X}$ \\
Ed-CH-5-FU-Cel-PM & 1345 & $\mathrm{~S}=0$ stretching \\
& 1227 & $\mathrm{C}-\mathrm{X}$ \\
Ed-CH-5-FU-Cel-MSs & 1148 & Eudragit S 100 \\
& 2912 & $\mathrm{OCH} / \mathrm{CH}_{3}$ \\
& 1647 & $\mathrm{C}=0$ \\
& 1241 & $\mathrm{C}-\mathrm{X}$ \\
\hline
\end{tabular}

FTIR: Fourier transform infrared spectroscopy, 5-FU: 5-Fluorouracil, Cel: Celecoxib, CH: Chitosan, MSs: Microspheres, PM: Physical mixture

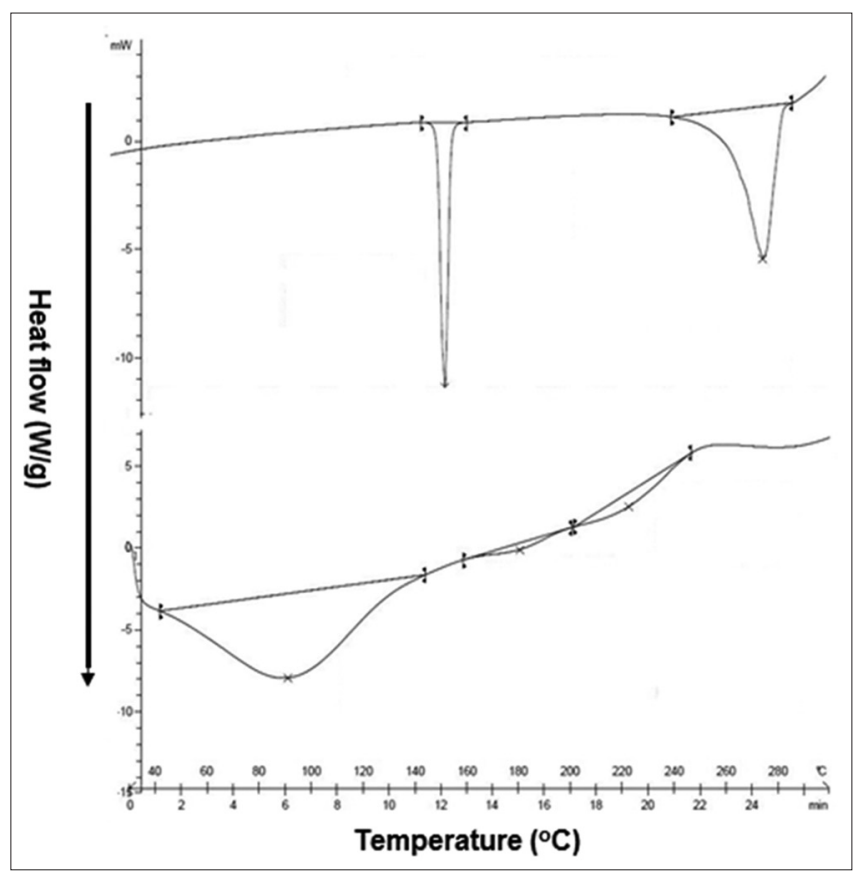

Fig. 1: Differential scanning calorimetry of (a) 5-FU-Cel-PM and (b) Ed-CH-5-FU-Cel-MSs estimated between $30^{\circ} \mathrm{C}$ and $300^{\circ} \mathrm{C}$. Each sample under investigation was scanned thrice, and the average of it was considered. 5-FU: 5-Fluorouracil, Cel: Celecoxib, $\mathrm{CH}$ : Chitosan, MSs: Microspheres, PM: Physical mixture, Ed: Eudragit S 100

the other side, Cel exhibited an endothermic peak at $275.87^{\circ} \mathrm{C}$ which is well matched with its reported melting point range of $280-282^{\circ} \mathrm{C}$. Ed-CH-5-FU-Cel-MSs presented a depressed and relatively broad endothermic peak at $90.90^{\circ} \mathrm{C}$ which corroborated amorphization of the crystal structure of the drugs [34].

\section{PXRD studies}

PXRD studies were carried out to determine the crystalline nature of the drugs under investigation. The XRD diffractograms (Fig. 2) of 5-FU and Cel exhibited the sharp and intense peaks, indicating the crystalline structure. While the diffractograms of Ed-CH-5-FU-Cel-MSs demonstrated, low intensity peaks designated to the amorphous lattice. This was consistent with the previous reports [33].

\section{Particle size analysis and surface morphology}

It is apparent from the results obtained from laser diffractometry, the mean particle size of Ed-CH-5-FU-Cel-MSs was found to be $4.8 \pm 1.1 \mu \mathrm{m}$ and $2.7 \pm 0.9 \mu \mathrm{m}$, respectively, for MSs prepared by emulsion 
polymerization method and nonaqueous solvent evaporation method with an insignificant difference (Unpaired t-test, $p>0.05$ ). The photomicrographs obtained from TEM indicated the spherical and uniform shape of the coated MSs without any distortion of surface texture (Fig. 3)

\section{Drug EE and drug loading capacity}

The results of drug EE and drug loading capacity of the Ed-CH-5-FUCel-MSs are expressed in Table 2. The drug EE for MSs developed by emulsion polymerization method was calculated to be $71.30 \pm 2.3 \%$ and $35.20 \pm 1.9 \%$ with significant difference (Unpaired t-test, $\mathrm{p}>0.05$ ) whereas the drug loading capacity was found to be in the range of $6.5 \mathrm{mg} / 10 \mathrm{mg}$ and $2.3 \mathrm{mg} / 10 \mathrm{mg}$ for 5 -FU and Cel, respectively. On the other hand, in case of MSs developed by nonaqueous solvent evaporation method, slight decrease in drug EE as well as in drug loading capacity was observed.

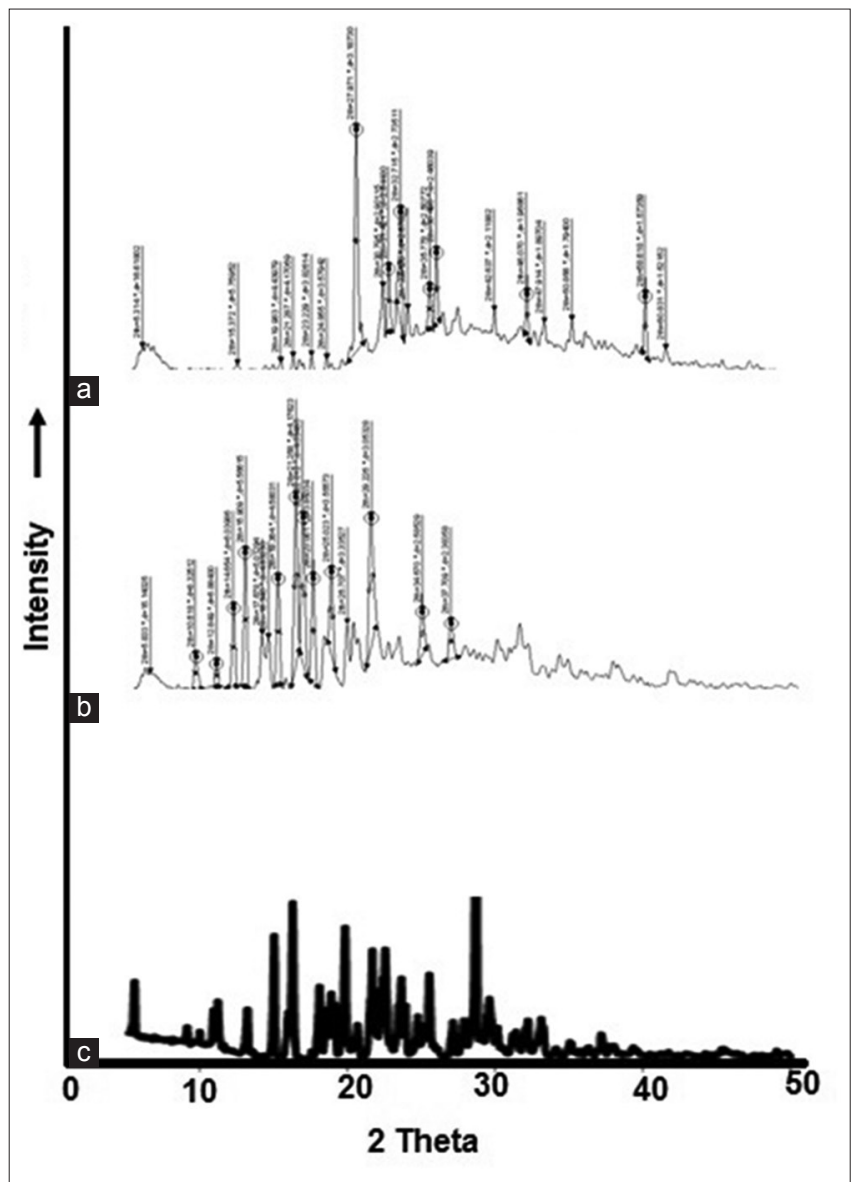

Fig. 2: Powder X-ray diffraction pattern of (a) 5-FU; (b) Cel, and (c) Ed-CH-5-FU-Cel-MSs measured between $10^{\circ}$ and $60^{\circ}$ at $2 \theta$ angle. Each sample was scanned thrice, and the average of that sample was considered. 5-FU: 5-Fluorouracil, Cel: Celecoxib, CH: Chitosan, MSs: Microspheres, Ed: Eudragit S 100

\section{Each experiment was carried out in triplicate $(\mathrm{n}=\mathbf{3})$} In vitro drug release studies

The formulation approach used in the development of Ed-CH-5-FUCel-MSs was to delay the release of the combination of drugs in the stomach and to get a controlled drug release for a relatively long duration, especially at the site of action, i.e., colon. Results obtained from in vitro drug release study met with the expected outcome. Dissolution study was carried out in $\mathrm{pH}$ progression medium at $37 \pm 0.5^{\circ} \mathrm{C}$. It is evident from the drug release study that at $0.5 \mathrm{~h}$, $97.5 \pm 1.1 \% 5$-FU was released as compared (two-way ANOVA test, $\mathrm{p}<0.01$ ) to $15.3 \pm 0.8 \%$ release of Cel from 5-FU-Cel-PM. Ed-CH-5-FUCel-MSs exhibited the release of $92.1 \pm 2.9 \%$ of 5 -FU in $8 \mathrm{~h}$ as compared (two-way ANOVA test, $\mathrm{p}<0.01$ ) to $18.9 \pm 0.7$ release of Cel after the same duration of time (Fig. 4).

Ed-CH-5-FU-Cel-MSs showed that there was no substantial amount of drug release (5-FU and Cel) in the initial $2 \mathrm{~h}$ in simulated gastric fluid ( $\mathrm{pH}$ 1.2). The release of both drugs under investigation started in intestinal $\mathrm{pH}$ and the maximum release observed in the colonic milieu, the site of action.

\section{In vitro cytotoxicity assay}

To investigate the synergistic effect of 5-FU and Cel combination in CRC, the standard cell proliferation assay was performed on pure drugs as well as on the developed formulations. Cytotoxicity of the 5-FU, Cel, 5-FU-Cel-PM, Ed-CH-5-FU-Cel-MSs, and Bl-MSs was studied against HT-29 cell line and expressed in terms of percentage cell viability (Fig. 5). The drug-loaded MSs exhibited appreciable potency against HT-29 cells with an $\mathrm{IC}_{50}$ value of $35.9 \pm 4.2 \mu \mathrm{M}$, which is notably lower than (One-way ANOVA test, $\mathrm{p}<0.05$ ) IC $_{50}$ value of pure Cel $(48.7 \pm 2.1 \mu \mathrm{M}), 5$-FU $(45.4 \pm 3.6 \mu \mathrm{M})$, and the combination of both drugs $(47.3 \pm 2.5 \mu \mathrm{M})$. Bl-MSs did not produce any cytotoxicity against HT-29 cells. The results exhibited the possible synergistic effect when Cel and 5-FU were used in combination. This strategy could be used as a potential approach for the management of CRC due to controlled release phenomena $[35,36]$.

\section{CONCLUSION}

In the present study, we have offered the oral drug delivery system in the form of MSs of 5-FU and Cel combination for the management of CRC. Carbohydrate polymer, $\mathrm{CH}$ was employed for the fabrication of MSs to enable the drug release in the colonic milieu. In addition, Ed coating has supported the tailored system to release the drug at the target site.

Our Eudragit coated carbohydrate based polymeric MSs of 5-FU and Cel combination will potentially improve the drug delivery in the colon while maintaining the high stability in the stomach and small intestine.

\section{ACKNOWLEDGMENT}

We are highly thankful to the management of Chandigarh College of Pharmacy for providing necessary facilities to carry out the research work. Moreover, we are highly thankful to Dr. Rupinder Sodhi for helping in cell line studies. The authors are also thankful to the SAIF, Punjab University, Chandigarh for the providing the facility of scanning electron microscopy and powder XRD.

Table 2: Particle size, EE, and drug loading capacity of the drug-loaded MSs (Ed-CH-5-FU-Cel-MSs)

\begin{tabular}{lll}
\hline Parameter & Emulsion polymerization method & Nonaqueous solvent evaporation method \\
\hline Particle size & $4.8 \pm 1.1 \mu \mathrm{m}$ & $2.7 \pm 0.9 \mu \mathrm{m}$ \\
EE & $71.30 \pm 2.3 \%(5-\mathrm{FU})$ & $70 \pm 1.7 \%(5-\mathrm{FU})$ \\
& $35.20 \pm 1.9 \%(\mathrm{Cel})$ & $34.64 \pm 1.5 \%(\mathrm{Cel})$ \\
Drug loading capacity & $6.5 \mathrm{mg} / 10 \mathrm{mg}(5-\mathrm{FU})$ & $6.4 \mathrm{mg} / 10 \mathrm{mg}(5-\mathrm{FU})$ \\
& $2.3 \mathrm{mg} / 10 \mathrm{mg}(\mathrm{Cel})$ & $2.32 \mathrm{mg} / 10 \mathrm{mg}(\mathrm{Cel})$ \\
\hline
\end{tabular}

EE: Entrapment efficiency, 5-FU: 5-Fluorouracil, Cel: Celecoxib, CH: Chitosan, MSs: Microspheres 


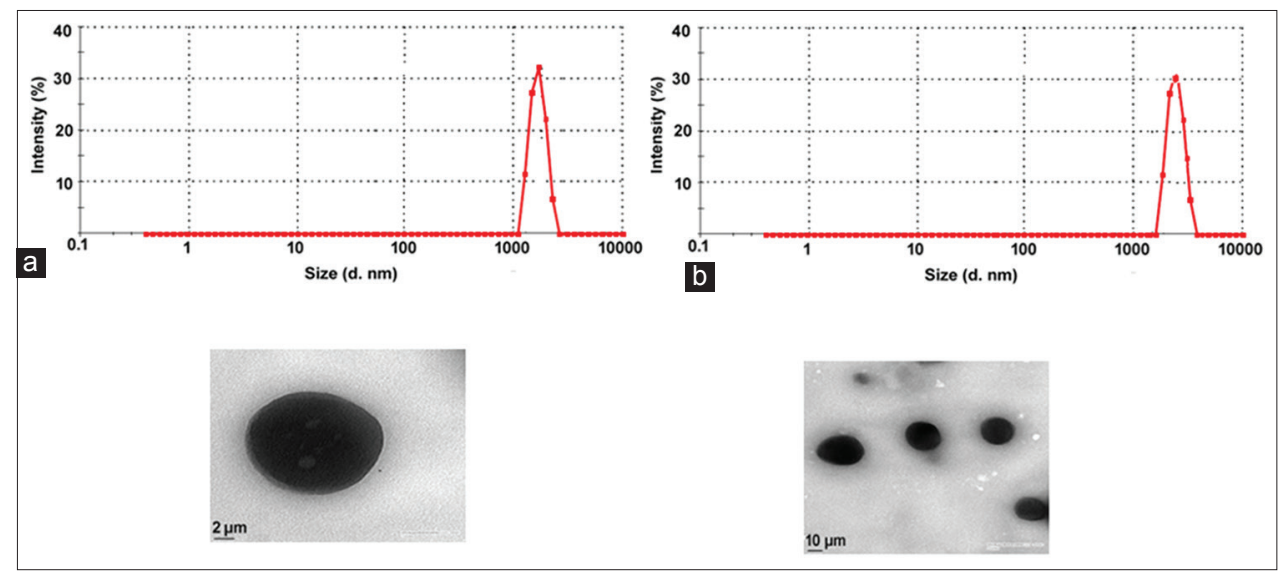

Fig. 3: Particle size distribution and transmission electron microscope of Ed-CH-5-FU-Cel-MSs prepared by (a) nonaqueous solvent evaporation method and (b) emulsion polymerization method. Each Experiment was carried out in triplicate (n=3). 5-FU: 5-Fluorouracil, Cel: Celecoxib, CH: Chitosan, MSs: Microspheres, Ed: Eudragit S 100

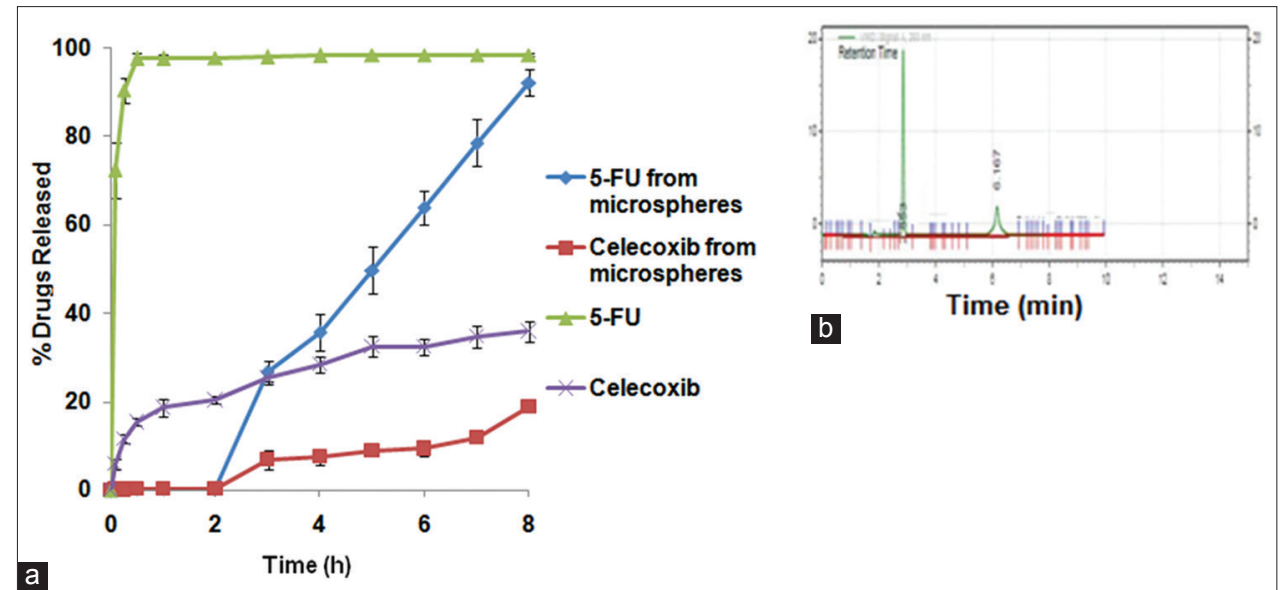

Fig. 4: (a) In vitro release profile of Ed-CH-5-FU-Cel-MSs in simulated gastric fluid followed by simulated intestinal fluid and finally in the simulated colonic fluid. The study was performed in triplicate (mean \pm standard deviation, $n=3$ ). (b) Representative chromatogram of drug release studied by high-performance liquid chromatography. 5-FU: 5-Fluorouracil, Cel: Celecoxib, CH: Chitosan, MSs: Microspheres, Ed: Eudragit $\mathbf{S} 100$

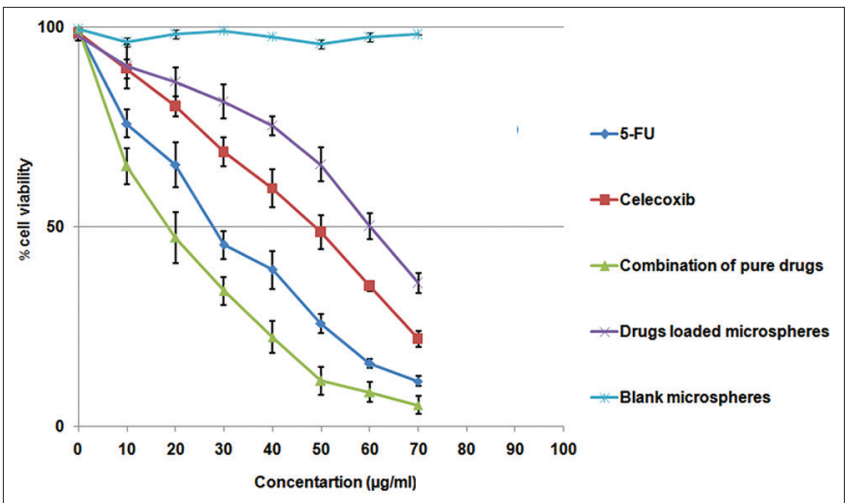

Fig. 5: Therapeutic efficacy testing of Ed-CH-5-FU-Cel-MSs against human colon cancer cells, HT-29. Each experiment was carried out in triplicate $(n=3) .5$-FU: 5-Fluorouracil, Cel: Celecoxib, CH: Chitosan, MSs: Microspheres, Ed: Eudragit S 100

\section{AUTHORS' CONTRIBUTIONS}

Vikas Bansal: Conceptualized the article, compiled full literature search and drafted the manuscript. Anjoo Kamboj: Supervisor of the research work, provided guidance in the preparation of a standard paper. Jitender Madan: Evaluated the manuscript and helped in statistical analysis.

\section{CONFLICTS OF INTEREST}

There are no conflicts of interest among authors.

\section{REFERENCES}

1. Siegel RL, Miller KD, Jemal A. Cancer statistics, 2017. CA Cancer J Clin 2017;67:7-30

2. Patel MM. Getting into the colon: Approaches to target colorectal cancer. Expert Opin Drug Deliv 2014;11:1343-50.

3. Gulbake A, Jain A, Jain A, Jain A, Jain SK. Insight to drug delivery aspects for colorectal cancer. World J Gastroenterol 2016;22:582-99.

4. Gupta RA, Dubois RN. Colorectal cancer prevention and treatment by inhibition of cyclooxygenase-2. Nat Rev Cancer 2001;1:11-21.

5. Ashwanikumar N, Kumar NA, Nair SA, Kumar GV. Methacrylic-based nanogels for the $\mathrm{pH}$-sensitive delivery of 5-fluorouracil in the colon. Int J Nanomedicine 2012;7:5769-79.

6. Zhang DQ, Guo Q, Zhu JH, Chen WC. Increase of cyclooxygenase-2 inhibition with celecoxib combined with 5-FU enhances tumor cell apoptosis and antitumor efficacy in a subcutaneous implantation tumor model of human colon cancer. World J Surg Oncol 2013;11:16.

7. Wacker A, Lersch C, Scherpinski U, Reindl L, Seyfarth M. High incidence of angina pectoris in patients treated with 5-fluorouracil. A planned surveillance study with 102 patients. Oncology 2003;65:108-12

8. Jensen SA. On 5-fluorouracil therapy of colorectal cancer. Dan Med J 2013;60:B4603

9. Giovannucci E, Rimm EB, Stampfer MJ, Colditz GA, Ascherio A, Willett WC, et al. Aspirin use and the risk for colorectal cancer and adenoma in male health professionals. Ann Intern Med 1994;121:241-6. 
10. Goldman AP, Williams CS, Sheng H, Lamps LW, Williams VP, Pairet M, et al. Meloxicam inhibits the growth of colorectal cancer cells. Carcinogenesis 1998;19:2195-9.

11. Rahman M, Selvarajan K, Hasan MR, Chan AP, Jin C, Kim J, et al. Inhibition of COX-2 in colon cancer modulates tumor growth and MDR-1 expression to enhance tumor regression in therapy-refractory cancers in vivo. Neoplasia 2012;14:624-33.

12. Steinbach G, Lynch PM, Phillips RK, Wallace MH, Hawk E, Gordon GB, et al. The effect of celecoxib, a cyclooxygenase-2 inhibitor, in familial adenomatous polyposis. N Engl J Med 2000;342:1946-52.

13. Ruiz JF, Kedziora K, Keogh B, Maguire J, Reilly M, Windle H, et al. A double prodrug for colon targeting of benzenesulfonamide COX-2 inhibitors. Bioorgan Med Chem Lett 2011;21:6636-40.

14. Finckh A, Aronson MD. Cardiovascular risks of cyclooxygenase-2 inhibitors: Where we stand now. Ann Intern Med 2005;142:212-4.

15. Lin C, Ng HL, Pan W, Chen H, Zhang G, Bian Z, et al. Exploring different strategies for efficient delivery of colorectal cancer therapy. Int J Mol Sci 2015;16:26936-52.

16. Rajesh K, Deveswaran R, Bharath S, Basavaraj BV. Development of mesalazine microspheres for colon targeting. Int J Appl Pharm 2017;9:1-9.

17. Jain A, Jain SK. Optimization of chitosan nanoparticles for colon tumors using experimental design methodology. Artif Cells Nanomed Biotechnol 2016;44:1917-26.

18. Shaima C, Moorthi PV, Kutty SN. In vitro anticancer activity of 5-fluorouracil coated chitosan nanoparticle. Int J Curr Pharm Res 2016;8:6-8.

19. Thakral NK, Ray AR, Majumdar DK. Eudragit S-100 entrapped chitosan microspheres of valdecoxib for colon cancer. J Mater Sci Mater Med 2010;21:2691-9.

20. Paharia A, Yadav AK, Rai G, Jain SK, Pancholi SS, Agrawal GP, et al. Eudragit-coated pectin microspheres of 5-fluorouracil for colon targeting. AAPS PharmSciTech 2007;8:12.

21. Raj BS, Nair RS, Samraj PI, Vidya. Formulation and evaluation of coated microspheres for colon targeting. J Appl Pharm Sci 2013;3:S68-74.

22. Jyoti K, Bhatia RK, Martis EA, Coutinho EC, Jain UK, Chandra R, et al. Soluble curcumin amalgamated chitosan microspheres augmented drug delivery and cytotoxicity in colon cancer cells: In vitro and in vivo study. Colloids Surf B Biointerfaces 2016;148:674-83.

23. Wang QS, Wang GF, Zhou J, Gao LN, Cui YL. Colon targeted oral drug delivery system based on alginate-chitosan microspheres loaded with icariin in the treatment of ulcerative colitis. Int J Pharm 2016;515:176-85.

24. Cerchiara T, Abruzzo A, di Cagno M, Bigucci F, Bauer-Brandl A,
Parolin $\mathrm{C}$, et al. Chitosan based micro-and nanoparticles for colontargeted delivery of vancomycin prepared by alternative processing methods. Eur J Pharm Biopharm 2015;92:112-9.

25. Patel KS, Patel MB. Preparation and evaluation of chitosan microspheres containing nicorandil. Int J Pharm Investig 2014;4:32-7.

26. Garud N, Garud A. Preparation and in vitro evaluation of metformin microspheres using non-aqueous solvent evaporation technique. Trop J Pharm Res 2012;11:577-83.

27. Sareen R, Jain N, Rajkumari A, Dhar KL. PH triggered delivery of curcumin from eudragit-coated chitosan microspheres for inflammatory bowel disease: Characterization and pharmacodynamic evaluation. Drug Deliv 2016;23:55-62.

28. Kumar M, Awasthi R. Development of metronidazole-loaded colontargeted microparticulate drug delivery system. Polim Med 2015;45:57-65.

29. Glavas Dodov M, Calis S, Crcarevska MS, Geskovski N, Petrovska V, Goracinova $\mathrm{K}$, et al. Wheat germ agglutinin-conjugated chitosan-caalginate microparticles for local colon delivery of 5-FU: Development and in vitro characterization. Int J Pharm 2009;381:166-75.

30. Kotla NG, Gulati M, Singh SK, Shivapooja A. Facts, fallacies and future of dissolution testing of polysaccharide based colon-specific drug delivery. J Control Release 2014;178:55-62.

31. Sharma A, Jyoti K, Bansal V, Jain UK, Bhushan B, Madan J, et al. Soluble telmisartan bearing poly (ethylene glycol) conjugated chitosan nanoparticles augmented drug delivery, cytotoxicity, apoptosis and cellular uptake in human cervical cancer cells. Mater Sci Eng C Mater Biol Appl 2017;72:69-76.

32. Lim YJ, Rhee JC, Bae YM, Chun WJ. Celecoxib attenuates 5-fluorouracil-induced apoptosis in HCT-15 and HT-29 human colon cancer cells. World J Gastroenterol 2007;13:1947-52.

33. Saini J, Bansal V, Chandra A, Madan J, Jain UK, Chandra R, et al. Bleomycin sulphate loaded nanostructured lipid particles augment oral bioavailability, cytotoxicity and apoptosis in cervical cancer cells. Colloids Surf B Biointerfaces 2014;118:101-10.

34. Rai G, Yadav AK, Jain NK, Agrawal GP. Eudragit-coated dextran microspheres of 5-fluorouracil for site-specific delivery to colon. Drug Deliv 2016;23:328-37.

35. Chakra BK, Karan S, Das B, Debnath S, Chatterjee TK. A controlled release microsphere formulation of an anti-diabetic drug and characterization of the microsphere. Int J Pharm Pharm Sci 2018;10:30-8.

36. Arafat M. Approaches to achieve an oral controlled release drug delivery system using polymers: A recent review. Int J Pharm Pharm Sci $2015 ; 7: 16-21$ 